\title{
APLICAÇÁO DE ECONOMIA COLABORATIVA EM EQUIPAMENTOS DE CONSTRUÇÃO
}

\author{
G. H. Pereira ${ }^{1}$; J. V. D. P. Longen ${ }^{2}$; A. Ryba ${ }^{3}$ \\ 1,2,3 UFPR - Centro Politécnico, Curitiba/PR \\ guilhermeh.pereira@gmail.com ${ }^{1}$,longenjv@gmail.com², andrea.ryba@ufpr.br ${ }^{3}$
}

Resumo: O presente trabalho é resultado do estudo de caso de uma startup, aqui denominada "Collabore", fundada e estruturada no ano de 2017, que idealizou uma prática de mercado que tem potencial de transformar parte da indústria da construção. A inovação do modelo de negócio estudado está relacionada com a utilização da economia compartilhada para intermediar a locação de equipamentos pesados de construção através de uma plataforma web. Para a estruturação desse artigo foi realizada uma imersão dentro desta recente empresa, através de uma pesquisa exploratória e descritiva, analisou-se os dados e características específicas do negócio com a finalidade de estudar acerca da aceitação, da eficácia e do potencial desse exemplo de inovação dentro de uma das indústrias mais antigas da humanidade. Dentre os dados obtidos, $42,11 \%$ dos entrevistados buscam fornecedores na internet e $88,24 \%$ estavam dispostos a experimentar a plataforma colaborativa. Pôde-se concluir entáo, que a referida ideia se apresenta como uma ótima oportunidade de negócio, capaz de influenciar a economia estadual, num plano imediato, e até a economia nacional, num plano mais ambicioso.

Palavras-chave: Economia colaborativa, Startup, Inovação, Equipamentos pesados de construção, Estudo de caso.

Abstract: The present article is the result of a case study of a startup, here called "Collabore", founded and structured during 2017, that idealized a Market practice that has the potential to change part of the construction industry. The innovation of this business model is related to the use of sharing economy to intermediate the lease of heavy construction equipment through a web platform. For the structuring of this study, an immersion was carried out within this new company, through an exploratory and descriptive research, data and specific characteristics of the business were observed with the purpose of concluding about the acceptance, effectiveness and potential of this type of innovation within one of the oldest industries of mankind. Among the data obtained, $42.11 \%$ of the interviewees looked for suppliers on the Internet and $88.24 \%$ were willing to try out the collaborative platform. It was concluded that "Collabore" is an idea that presentes itself as a great business opportunity, capable of influencing the local economy very soon, and even the national economy, on a more ambitious approach.

Keywords: Sharing economy, Startup, Innovation, Heavy equipment of constrution, Case study. 


\section{Introduçáo}

A indústria da construção funciona como um verdadeiro "motor econômico", possuindo uma grande capacidade de impactar a economia de qualquer país através da geração de empregos e riquezas. No Brasil, essa situação é ainda mais acentuada, visto que o setor de construção é líder na geração de empregos e representa aproximadamente 5,6\% do Produto Interno Bruto (PIB) industrial nacional [1]. A relevância desse mercado está relacionada com o fato de que a cadeia de suprimentos é quase integralmente nacionalizada: cerca de $98 \%$ dos insumos utilizados na construção são de origem brasileira [2].

$\mathrm{Na}$ Figura 1 é possível observar os gráficos que detalham, respectivamente, a participação de cada setor no PIB brasileiro em 2016 (lado esquerdo) e o percentual de cada atividade dentro do setor de indústria (lado direito), conforme estatísticas de [1].

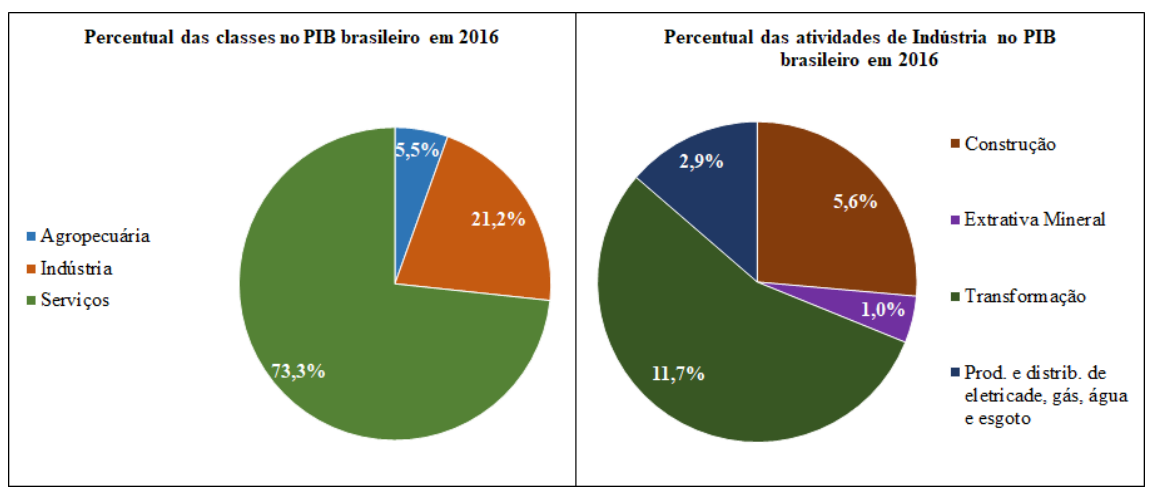

Figura 1 - Participação percentual das classes e respectivas atividades da indústria no PIB brasileiro para o ano de 2016.

Para que a indústria da construção mantenha o seu protagonismo é fundamental que haja uma mudança cultural, deixando de lado suas características rudimentares e sendo mais receptiva a novas tecnologias. Segundo o economista e empreendedor com foco em inovaçáo Arie Halpern, o setor de construção no Brasil está atrasado em relação à indústria dos Estados Unidos e de países da Europa, mercados onde a construção é um dos setores que mais investem em novas tecnologias [3].

Um dos principais nichos, dentro do setor da construção, que carece de inovaçôes é o setor de locação de equipamentos. A locação tem papel fundamental na redução dos custos das construtoras, segundo Graciana Méndez - analista de consumo da consultoria inglesa Mintel - o aluguel é uma das formas encontradas pelo construtor para manter o nível de vida em momentos de crise econômica [4]. Levando em consideração a relevância que esse segmento possui dentro da indústria da construção, a adequação e implementação de inovaçôes são de suma importância para aquelas empresas que buscam se diferenciar e se destacar dentro desse mercado. Um dos motivos é que pode representar uma agregação de valor aos seus serviços. 
É nesse cenário de urgência por renovação do setor construtivo que se percebeu a necessidade da criação da startup "Collabore”, nome fictício dado à empresa para evitar conflitos de interesses, cujo mercado de atuação está inserido na locação de equipamentos pesados. Basicamente, a ideia é utilizar a economia colaborativa no mercado de locação de equipamentos pesados. Assim, o objetivo deste estudo foi analisar a aplicabilidade de uma startup que traz em seu modelo de negócio o conceito de economia colaborativa para o aluguel de equipamentos pesados de construção.

\subsection{Referencial teórico}

Nesse contexto, emerge o conceito de economia colaborativa, que de acordo com [5], são novos tipos de modelos de negócio, que, em sua grande maioria, são suportados por ideias, propostas, produtos e serviços totalmente disruptivos que são viabilizados pela tecnologia e pelo acesso e compartilhamento que a Internet propicia. Tais produtos e serviços são entregues a partir de plataformas e de dispositivos móveis. Seu rápido acesso e sua fácil utilização colaboram para o desenvolvimento e/ ou reposicionamento desses modelos de negócios, associados às diferentes formas de relaçóes comerciais, econômicas e sociais, consequentemente, proporcionam um novo tipo de engajamento social e econômico.

Em 1978, utilizou-se pela primeira vez o termo "consumo colaborativo" [6], mas somente na década de 1990, nos Estados Unidos, que o termo foi colocado em prática impulsionado pelos avanços tecnológicos que propiciaram a reduçáo dos custos das transaçóes on-line peer-to-peer [7], termo também conhecido por "P2P" que tem sua origem na língua inglesa, significando "ponto-a-ponto" ou "par-a-par".

Também conhecida como economia compartilhada ou economia em rede, de acordo com [8], ela viabilizou a criaçáo de novos modelos de negócio baseados na troca e no compartilhamento de bens e serviços entre pessoas desconhecidas. O que fez com que o conceito fosse popularizado, permitindo um número cada vez maior de novos modelos de negócio [9]. Além disso, o avanço da tecnologia da informação possibilitou a expansão deste modelo através de plataformas acessíveis ao público. Como exemplo práticos temos o Airbnb, que possibilita o compartilhamento de aluguel de quartos, apartamentos e residências.

Assim, o presente trabalho buscou o emprego de economia colaborativa num ramo que necessita de inovaçốes e de novas tecnologias - equipamentos de construção - para manter a sua participação na economia brasileira e a sua contribuição para a o desenvolvimento do país. Esse pretexto foi utilizado como justificativa para a elaboração desse estudo, que abordará um tema principal: a economia colaborativa servindo como uma ferramenta de inovaçáo e de aperfeiçoamento tecnológico. Para a aplicação desse "novo" conceito será utilizada a empresa de nome fictício "Collabore", mencionada anteriormente, como objeto de estudo de caso, com o propósito de gerar uma visão mais clara da 
efetividade do modelo de negócio proposto e com a finalidade de avaliar a aceitação, a eficácia e o potencial desse tipo de inovação.

\section{Metodologia}

\subsection{Procedimentos metodológicos}

Pesquisas usualmente são classificadas com base em seus objetivos gerais, dividindo-se normalmente em três grandes categorias: as exploratórias, as descritivas e as explicativas [11]. A primeira delas estabelece métodos para a elaboração de uma pesquisa e visa oferecer informações sobre o objeto desta e ainda orienta a formulaçáo de hipóteses [12]. Na pesquisa descritiva, realiza-se o estudo dos fatos do mundo físico sem a interferência do pesquisador [13]. Por fim, segundo [14], a pesquisa explicativa registra fatos, analisa-os, interpreta-os e identifica suas causas com a finalidade de definir modelos teóricos e gerar hipóteses ou ideias através de deduçôes lógicas.

A metodologia de pesquisa adotada para a realização do presente estudo pode ser enquadrada como uma pesquisa exploratória e descritiva; exploratória pelo fato de serem estabelecidos múltiplos critérios, métodos e técnicas para atingir todos os objetivos propostos e descritiva por envolver a investigação de eventos sem a mediação dos pesquisadores. A primeira etapa foi a elaboração da entrevista, com subsequente aplicação prática durante 4 meses, com foco em empresas do ramo da construção civil, todas elas localizadas na Região Metropolitana de Curitiba, selecionadas através de pesquisa por palavras chave em sites de busca online e catálogos municipais. A análise, elaboração de tabelas e diagramação dos dados foi realizada através do software Microsoft Excel.

\subsection{Estudo de caso}

A “Collabore" é considerada uma startup; segundo definição de [15] é uma empresa que está em busca de um modelo de negócios viável que seja repetível e escalável, cuja característica é ser capaz de vender o mesmo produto para todos os clientes, dispondo da possibilidade de se desenvolver sem precisar elevar seus custos básicos de operação, ou seja, são modelos de gestão que permitem que as empresas façam mais com menos.

Através do conceito de economia colaborativa, a "Collabore" explora o mercado de locação de equipamentos pesados da linha amarela por meio de uma plataforma online, tendo como fornecedores as empresas proprietárias de equipamentos e tendo como principais clientes as construtoras interessadas em alugá-los. As propostas fundamentais da empresa são: de um lado, reduzir ao máximo a ociosidade dos equipamentos, gerando renda aos proprietários e, por outro lado, diminuir o tempo despendido na busca e fechamento de contratos de locação, reunindo uma grande variedade de equipamentos em um só lugar, como exemplificado na Figura 2, facilitando muito o processo de locação. 


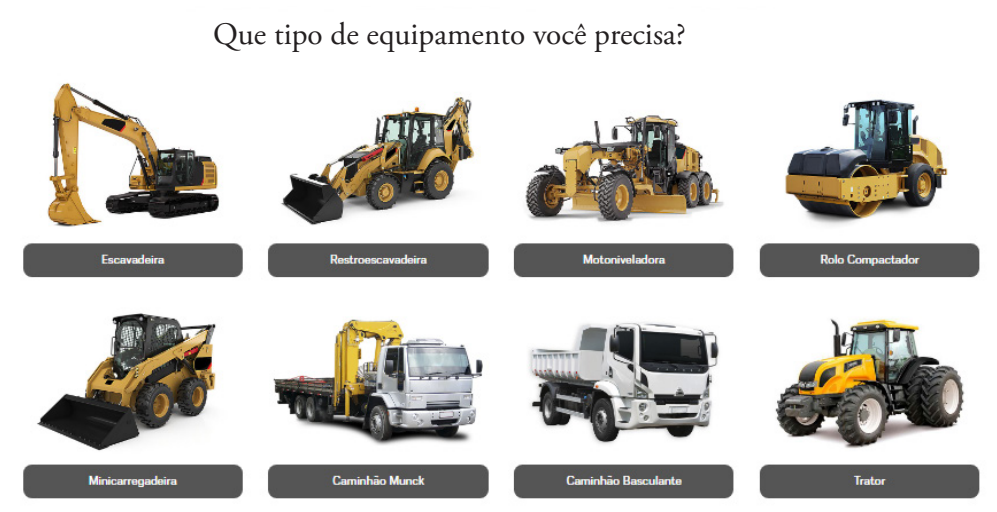

Figura 2 - Seleção dos equipamentos para locação na Plataforma da “Collabore”.

A receita da "Collabore" é garantida através de uma comissão aplicada em cima do valor de cada transação realizada pelo site, essa comissão depende do tipo de equipamento locado e gira em torno de $8 \%$. Fora do Brasil, existem algumas empresas com modelos de negócios similares que já são referências mundiais para o setor de aluguel de equipamentos pesados, dentre elas podem ser citadas: a canadense Dozr e as americanas EquipmentShare e YardClub.

Das salas de aula da Universidade Federal do Paraná até atingir a abrangência nacional, essa é a visão da jovem empresa que iniciou as atividades em 2017. Hoje, a "Collabore" conta com um time mais estruturado, com cientistas da computação em seu corpo de colaboradores. Contudo, no primeiro semestre de 2017, foi umas das poucas iniciativas do país selecionadas para o programa de aceleração do Instituto TIM, chamado AWC (Academic Working Capital), em que recebe um apoio financeiro para validações e estruturação do negócio.

O setor de aluguel de equipamentos brasileiro ainda não conta com nenhuma iniciativa similar às estrangeiras. Desta forma, a "Collabore" busca ser a primeira iniciativa a aproveitar esse espaço existente no mercado brasileiro, cujo tamanho atual, segundo estimativa da Analoc (Associação Brasileira dos Sindicatos e Associaçóes Representantes dos Locadores de Máquinas, Equipamentos e Ferramentas), é de 4,5 bilhóes de reais.

\section{Resultados}

\subsection{Dificuldades iniciais}

O Brasil, devido a sua reconhecida burocracia, não facilita o início de novos empreendimentos, a legislação confusa e a grande quantidade de tributos são alguns dos obstáculos que um empreendedor deve enfrentar ao criar seu próprio negócio. Em levantamento realizado pelo Banco Interamericano de Desenvolvimento (BID), em 2001, com 1271 empreendimentos, pode-se destacar na Tabela 1, algumas das principais dificuldades enfrentadas pelos empresários brasileiros durante os 3 primeiros anos de operação [16]. 
Tabela 1 - Principais dificuldades enfrentadas pelos empreendedores brasileiros ao iniciar um novo negócio.

\begin{tabular}{cc}
\hline Problemas & Total (\%) \\
\hline Ter um fluxo de caixa equilibrado & 80,7 \\
Conseguir clientes & 75,9 \\
Contratar empregados qualificados & 73,5 \\
Adquirir máquinas e equipamentos adequados & 60,2 \\
Obter informaçóes de mercado & 54,8 \\
Conseguir fornecedores adequados & 53 \\
\hline
\end{tabular}

Todas as dificuldades apresentadas na Tabela 1 podem ser enxergadas como riscos para o modelo de negócios proposto pela "Collabore". Ao longo da concepção da empresa, foi observada como uma dificuldade principal a busca por novos clientes e fornecedores; pelo fato de ser algo extremamente novo no país.

\subsection{Dados das entrevistas}

Ao longo de aproximadamente 4 meses, foram conduzidas 45 entrevistas com empresas do ramo da construção civil, todas elas localizadas na Região Metropolitana de Curitiba, a fim de se conhecer melhor a opinião dos agentes envolvidos nesse modelo de negócio. Desse total, 28 entrevistas foram com empresas consideradas locatárias (clientes) e 17 com locadoras (fornecedores). A partir das respostas recebidas, foi elaborada a Figura 3, com base nas informaçóes mais relevantes para a proposta da "Collabore".

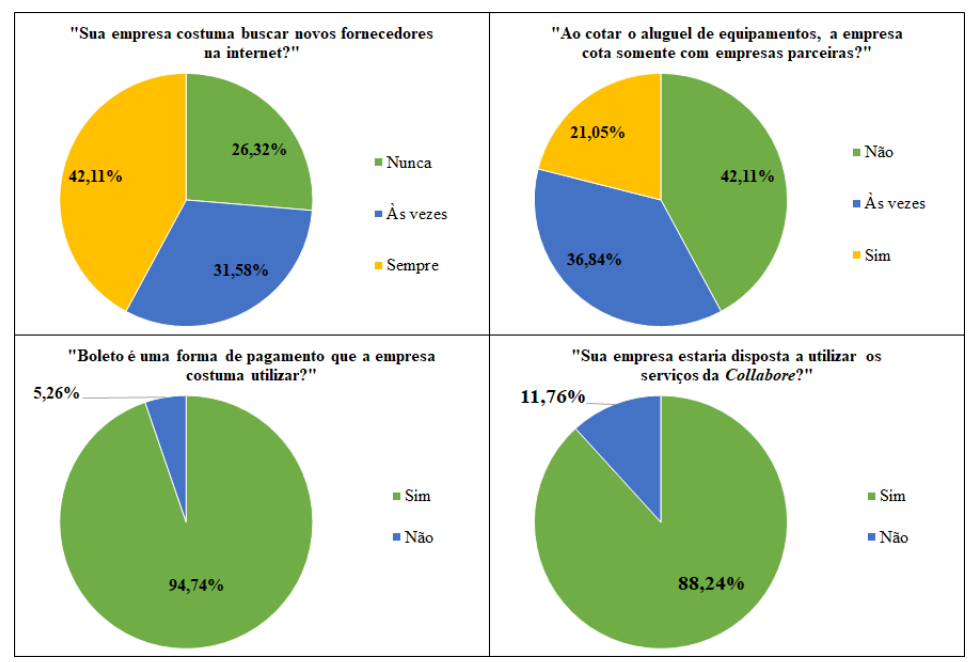

Figura 3 - Compilação das respostas mais relevantes coletadas durante as entrevistas. Fonte: Os autores (2017). 
Com a realização da pesquisa, buscou-se, então, apenas um conhecimento da visão de possíveis clientes acerca dessa nova ideia de negócio e sua aceitação em um panorama mais local. Por isso, pode-se deduzir que os dados coletados são extremamente favoráveis ao modelo de negócios que a "Collabore" está propondo. Tendo como referência as informaçóes compiladas na Figura 3, pode-se perceber que a vasta maioria das empresas já utilizam o meio digital como forma de buscar fornecedores para a locação de equipamentos. Constata-se também que cerca de $80 \%$ das empresas consideram recorrer a novos fornecedores ao realizar uma cotação.

\subsection{Benefícios econômicos}

Contabilizando o período entre os meses de abril e setembro de 2017, foram realizadas 10 operaçóes mediadas pela "Collabore", incluindo operaçóes com retroescavadeiras, miniescavadeiras, minicarregadeiras, caminhóes e gruas. Essas intermediaçóes geraram uma receita de aproximadamente 320 mil reais para as construtoras que disponibilizaram seus ativos ociosos. Um outro ponto importante foi que a "Collabore" propiciou aos seus clientes, ao longo dessas operações, uma diminuição dos valores dos aluguéis dos equipamentos, redução essa que atingiu 15\% quando comparado aos preços praticados pelo mercado de locaçóes da Regiáo Metropolitana de Curitiba, o que gerou uma economia aos locatários de aproximadamente 50 mil reais.

\section{Conclusóes}

A aplicação do conceito da economia colaborativa no ramo de locação de equipamentos pesados apresenta-se como sendo uma ferramenta inovadora bastante útil para a construção civil, principalmente em momentos de crise no setor. Essa nova ideia de negócio apresenta-se promissora tanto para proprietários de máquinas quanto para os locatários destas. Para os primeiros, por evitar manter grandes volumes de ativos parados nas empresas, sem gerar rendimentos, e para os locatários, por servir como uma excelente fonte de economia de recursos, conseguindo realizar locaçóes por valores menores do que praticados no mercado. Além disso, impacta nesse mercado em termos de competitividade, já que disponibiliza um serviço já existente, porém a um preço abaixo do que já é praticado.

Diante disso, torna-se evidente o potencial que a "Collabore" possui de impactar o mercado de locaçóes de equipamentos, mais especificamente da linha amarela. Em menos de 1 ano de atividade, um total de 20 empresas - dentre clientes e fornecedores - foram influenciadas positivamente pelos serviços da empresa. Considerando que uma startup é uma empresa facilmente escalável, é plausível concluir que a "Collabore" tem a capacidade, em poucos anos, de influenciar a economia estadual e, num plano mais ambicioso, até a economia nacional. 


\section{Referências}

[1] INSTITUTO BRASILEIRO DE GEOGRAFIA E ESTATÍSTICA - IBGE, 2016; Indicadores IBGE. Disponível em: <ftp://ftp.ibge.gov.br/Contas_Nacionais/Contas_Nacionais_Trimestrais/Fasciculo_Indicadores_IBGE/pib-volval_201604caderno.pdf>. Acesso em: 18 out. 2017.

[2] OLIVEIRA, 2012; Insumos na construção civil brasileira. Disponível em: <www.bibliotecadigital.unicamp.br/ document/?down=000898381>. Acesso em: 7 jul. 2017.

[3] EXAME, 2016; Arie Halpern: a nova construçáo civil será disruptiva. Disponível em: <https://exame.abril.com. br/negocios/dino/arie-halpern-a-nova-construcao-civil-sera-disruptiva-dino89095510131/>. Acesso em: 17 out. 2017.

[4] O GLOBO, 2016; Na crise, locação ganha adeptos e procura cresce até 90\%. Disponível em: <https://oglobo. globo.com/economia/na-crise-locacao-ganha-adeptos-procura-cresce-ate-90-19644448>. Acesso em: 17 out. 2017.

[5] KOTLER, P.; KARTAJAYA, H.; SETIAWAN, I. Marketing 3.0: As forças que estão definindo o novo marketing centrado no ser humano. Rio de Janeiro: Elsevier, 2010.

[6] FELSON, M.; SPAETH, J. L. Community structure and collaborative consumption: a routine activity approach. The American Behavioral Scientist. 1978.

[7] SHIRKY, C.L.A.Y. Lá vem todo mundo: o poder de organizar sem organizaçóes. Rio de Janeiro: Zahar. 2012.

[8] SCHOR, J. Debating the sharing economy. Great transition initiative. 2014.

[9] GANSKY, L. The mesh: why the future of business is sharing. Nova Iorque: Penguin. 2010.

[10] BOTSMAN, R.; ROGERS, R. O que é meu é seu: como o consumo colaborativo vai mudar o nosso mundo. Porto Alegre: Bookman. 2009.

[11] VIANNA, I. O. de A. Metodologia do trabalho científico: um enfoque didático da produção científica. Editora Pedagógica Universitária (E.P.U.), 2001.

[12] CERVO, A. L.; SILVA, R. da. Metodologia científica. Prentice Hall Brasil: 2006.

[13] BARROS, A. J. P.; LEHFELD, N. A. de S. Fundamentos de metodologia científica. Makron: 2007.

[14] LAKATOS, E. M.; MARCONI, M. de A. Metodologia científica. Atlas Editora: 2011.

[15] BLANK, Steve; DORF, Bob. The startup owner's manual. K \& S Ranch: 2012.

[16] SOUL STARTUPS; As principais dificuldades dos empregadores nos anos iniciais. Disponível em: <http:// blog.soulstartups.com.br/principais-dificuldades-empreendedores-anos-iniciais/>. Acesso em: 18 out. 2017. 